\author{
Hosseni Ali GHAFFARI, M.S. Student \\ E-mail: behzadghaffari233@yahoo.com \\ Associate Professor Vahidreza GHEZAVATI, PhD \\ E-mail: v_ghezavati@azad.ac.ir (Corresponding Author) \\ School of Industrial Engineering, Islamic Azad University \\ South Tehran Branch, Tehran, Iran
}

\title{
A FUZZY MODELING FOR DETERMINING FEASIBILITY OF CASH FLOWS USING AN EFFICIENT AND NOVEL IRR METRIC
}

\begin{abstract}
Internal rate of return (IRR) method is one of the most useful methods for the economic evaluation of projects and the determination of their desirability and profitability. However, this method suffers from serious disadvantages. Although researchers attempt to eliminate the major deficiencies, some drawbacks are still not resolved. The most important drawbacks in the last techniques are regarded to inconsistent results from the economic point of view for some projects and also accelerating growth of vector values of investment flow in which causes difficulties to find the solution. In this paper, we aim to overcome such drawbacks by developing an efficient method for computing the IRR method for projects, which is called "modified average internal rate of return". Since, the value of parameters such as incomes, investments, inflation rate and etc is not a certain value, this method is developed for two conditions: certain and fuzzy conditions. Finally, the paper analyzes the validity of the obtained results by simulation and using @RISK software for many numerical examples. The results indicate that the new method proposed in this paper works properly and can eliminate previous disadvantages.

Keywords: Economic evaluation of project, Fuzzy sets theory, Internal rate of return, @Risk, Cash flow, simulation.
\end{abstract}

\section{JEL Classification: C61}

\section{Introduction}

Nowadays, production initiatives and industrial projects are considered a commonest phenomenon of economic planning in different countries. These activities are suggested in different forms and scales with different amounts of investments and incomes. Therefore, correct decision making related to execute or not to execute of a certain project for establishing a production or industrial unit is one of the factors of success or failure for that unit. One of the common methods for computing economic feasibility and selecting the most economical projects is

DOI: 10.24818/18423264/53.1.19.15 
Hossein Ali Ghaffari, Vahidreza Ghezavati

the rate of return method (ROR). In fact, balancing the incomes (including annual incomes, residual value, etc) and costs (including initial investment, annual costs, etc) is represented by one possible rate and that is IRR method (Weber, 2014).

IRR method is more understandable since it can be compared to a bank rate against net present value, and net equivalent uniform annual methods. Therefore, there are more inclinations towards using the IRR method.

Despite the aforementioned advantages, the IRR method still has major disadvantages, which should be considered when using this method (Guerra et. al., 2014). These problems are as follows:

a) Once IRR method is a complex-valued, possibility of such value is questionable.

b) When the market rate is variable during different periods, defining economic feasibility of the projects by IRR method is impossible.

The previous methods still have two major drawbacks that are solved in this paper in both certain and fuzzy conditions. The first disadvantage with the last method is that once the initial value of a cash flow is not a suitable indicator for other values of a cash flow project, the numerical value obtained will be inconsistent from the economic point of view. The second disadvantage with the last method is the accelerating growth of vector values of investment flow, with the increased of life length value and the dependent vector values of investment flow on the initial value of cash flow stream. The second drawback causes difficulties to find the solution. The details of the stated drawbacks are described in section 2.5.

The rest of the paper is organized as follows. In section 1, a literature survey will be presented. Section 2 presents different methods of computing IRR. At the end of this section (section 2.5), mathematical and numerical aspects of previous disadvantages and our novelties will be proposed. Section 3 proposed our new method in certain conditions. We will propose the new method under fuzzy conditions and the required computational results in section 4. Finally, conclusion and future directions will be described.

\section{Background and related work \\ 2.1 Literature review}

The concept of IRR will be elaborated which was introduced by Keynes (1937) for the first time. Brealey et al. (2012) rated a number of projects based on the IRR and showed that the above problem can be solved by analysis of the developmental differences between the two alternatives. Keirulff (2008) elaborated on the existing problems in the discussion of the net present value (NPV) and IRR and explained the method of applying IRR for solving the main weaknesses of NPV. Osborne (2010) used all kinds of IRR methods, including real, complexvalued, positive or negative to discuss a new approach towards inconsistency of projects which are rating based on the NPV and IRR Then, he introduced a new formula between NPV and IRR. Hazen (2009) defined a cash flow stream based on 
A Fuzzy Modeling for Determining Feasibility of Cash Flows Using an Efficient and Novel IRR Metric

the net investment flow or net borrowings flow and introduced a new approach where it could solve multi-rate problems and lack of internal rate of return investment.

Magni (2010a) introduced a new approach towards several problems of the IRR method. In his suggested method, there is no need for calculation of IRR method in a cash flow stream but he defined a desired flow vector of investment and used the concept of average internal rate of return (AIRR) to provide a new method. Magni (2011b) introduced another new approach which rated and defined economic feasibility of the projects by definition of aggregated return on investment (AROI). The most significant advantage of this method is no need for the market rate. Magni (2013c) introduced an economic average internal rate of return (EAIRR) which could solve the majority of the problems in the field of IRR method, though it cannot attribute a certain numerical value to the IRR scale for all the cash flows.

A robust optimization methodology was applied by Bas (2014) in order to handle uncertainty decisions related to NPV and IRR methods. This objective was done through a comparison between classical robust optimization methodology and economical decisions when cash flows are uncertain.

In real-world conditions, the value of parameters such as incomes, investments, inflation rate, market rate, and etc may not be a certain value and it may change over the period of time (Guerra et. al., 2014). Therefore, estimation of the cash flow stream is difficult and even almost impossible for some projects (Ucal Sari and Kahraman, 2015). For this purpose, some parts of this paper are related to the fuzzy theory, the concepts and theories of fuzzy sets are briefly described (Chen and Tsaur, 2016). Yao et al. (2005) developed the traditional formulation of discounted cash flows. The objective was considering random data for cash flows of a company. Guerra et al. (2014) proposed that uncertainty can be modelled by fuzzy intervals numbers. They used this ability to develop AIRR method.

Dubois and Parade (1980) completed fuzzy theory and introduced fuzzy numbers with different membership functions and the inverse function of membership functions and then elaborated on the method of calculation of algebraic operations. It should be noted that the vertex method was introduced by Dong and Shah (1986) to evaluate the functions with fuzzy variables. Kuchta (2008) also used different cuts of fuzzy values in the cash flow stream to introduce a method for obtaining the fuzzy internal rate of return (FIRR), which has its own advantages. The EasyClustering test platform - an integrated clustering Guerra and Sorini (2012) follow the Kuchta (2000) methodology with specific consideration to the parametric representation of fuzzy sets. In research by Appadoo et al. (2008) the concept of possibilistic mean and variance is developed to apply for fuzzy numbers and used to the calculation of the fuzzy net present value for future cash 
flows. Also, in research by Huang (2008), the fundamental hypothesis is in which fuzzy variables can indicate uncertainty of investment, annual net cash flows, and investment capital.

\subsection{Previous methods}

\subsubsection{The Method of Average Internal rate of Return}

In this approach (Magni, 2013), there is no need to calculate rate(s) of IRR for a cash flow stream. However, the analyzer should select the desired investment flow vector and then uses equation (2) to calculate values of interest rate vector. Finally, economic feasibility of project $\mathrm{X}$ is defined by using average weightings of value of the interest rate vector. Magni introduced this weighting average of interest rates under the concept of average internal rate of return (AIRR) which is done through the following formula:

$$
\begin{gathered}
\overline{\mathrm{K}}=\frac{\sum_{1}^{\mathrm{T}} \mathrm{k}_{\mathrm{t}} \cdot \mathrm{c}_{\mathrm{t}-1} \cdot(1+\mathrm{r})^{-(\mathrm{t}-1)}}{\operatorname{PV}(\mathrm{C} \mid \mathrm{r})} . \\
\mathrm{c}_{\mathrm{t}}=\mathrm{c}_{\mathrm{t}-1}\left(1+\mathrm{k}_{\mathrm{t}}\right)-\mathrm{x}_{\mathrm{t}}, \mathrm{t}=1,2, \ldots, \mathrm{T}, \mathrm{c}_{0}=-\mathrm{x}_{0}, \mathrm{c}_{\mathrm{T}}=0
\end{gathered}
$$

\subsubsection{The simple arithmetic mean}

If in AIRR method, the investment flow is defined in the form of $\mathrm{C}_{\mathrm{t}}=-\mathrm{x}_{0}(1+\mathrm{r})^{\mathrm{t}}$ with $\mathrm{CT}=0$, then the project's AIRR will be a simple arithmetic mean of the interest rate values.

The AIRR is a weighted average where the weights are capitals discounted at the market rate (Guerra et. al., 2014).

\section{Developing modified average internal rate of return in certain conditions}

In this section, this paper develops simple arithmetic mean method and introduces a new method entitled modified average internal rate of return (MAIRR) to solve the above mentioned disadvantages in a certain and deterministic conditions.

\subsection{Conceptual framework for MAIRR method:}

In this method, a V operation is defined first, which causes the initial value of cash flow to be a suitable indicator for the other cash flow values. Then, the vector of investment flow as $C_{t}=\frac{-x_{0}}{(1+r)^{t}}$ which has two side effects: dependency of the vector values of investment flow decrease to reach below the 
A Fuzzy Modeling for Determining Feasibility of Cash Flows Using an Efficient and Novel IRR Metric

initial value of cash flow; and exponential increasing of the vector values of investment flow with increasing of time can be avoided. In the following, MAIRR method is implemented in the form of an algorithm.

\subsection{Proposing MAIRR method:}

Consider the cash flow stream $\mathrm{X}=\left(\mathrm{x}_{0}, \mathrm{x}_{1}, \ldots, \mathrm{x}_{\mathrm{T}}\right)$ and the market rate is $r$. The following steps are suggested for calculation of IRR based on the MAIRR method.

a. If the sign of the initial value $\left(\mathrm{X}_{0}\right)$ of a cash flow is negative (positive), then the present value of only negative flows (positive) is computed and it is called $\mathrm{W}$.

b. Add a neutral operator $\mathrm{V}=\left(\left(\mathrm{W}-\mathrm{x}_{0}\right), 0,0, \ldots,\left(\mathrm{x}_{0}-\mathrm{W}\right) \cdot(1+\mathrm{r})^{\mathrm{T}}\right)$ to the cash flow

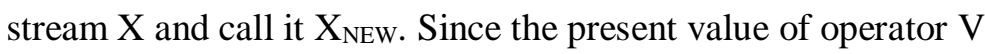
under the market rate $r$ equals zero, so the present value of cash flow $\mathrm{X}_{\mathrm{NEW}}$ under the market rate $\mathrm{r}$ will be equal to the present value of the cash flow $\mathrm{X}$.

c. The investment flow vector is computed based on the cash flow stream $\mathrm{X}_{\mathrm{NEW}}$ and equation $=\frac{-x_{0}}{(1+r)^{t}}$, and then the values of interest rate vector $(\mathrm{Kt})$ are computed.

$$
K=\frac{\sum_{1}^{T} k_{t} \cdot c_{t-1}(1+r)^{-(t-1)}}{P V(C \mid r)} \text { the value of }
$$

d. Finally, by using equation
MAIRR is computed. (Parameter K shows the value of MAIRR).

\subsection{The use of MAIRR for accept/reject decisions}

Now, a decision maker can determine the economic feasibility of a project $\mathrm{X}$ in the following manner:

a. If the present value of investment flow vector is greater than zero $(P V(C \mid r)>0)$, then the cash flow stream $\mathrm{X}$ is economical if and only if the value of MAIRR is greater than market rate.

b. If the present value of the cash flow stream is smaller than zero $(P V(C \mid r)<0)$, then the cash flow stream $\mathrm{X}$ is economical if and only if the MAIRR is less than market rate $(\mathrm{K}<\mathrm{r})$. 
Hossein Ali Ghaffari, Vahidreza Ghezavati

Example B. Consider the cash flow stream X26 $=(-20,30,-30,70)$ and assume that the market rate is $10 \%$. The present value of the above cash flow is 35.07. Therefore, based on the method of PV, the cash flow X26 is economical. To define the economic feasibility of the above cash flow based on the proposed MAIRR method, one should first calculate the value of parameter W. Because the initial value of the cash flow is negative, the value of $\mathrm{W}$ equals to present value of negative flows of cash flow X26 under the $10 \%$ market rate $(\mathrm{W}=-44.79)$.

$X=(-20,0,-30,0)$ $\mathrm{PV}=-44.79$

Then the amounts of neutral operator $\mathrm{V}$ vector are added to the cash flow stream $\mathrm{X}$ to obtain the cash flow stream XNEW.

$$
\begin{aligned}
& \mathrm{V}=\left(-44.79-(-20), 0,0,24.79 \times 1.1^{3}\right)=(-24.79,0,0,33) \\
& \mathrm{X}_{\mathrm{NEW}}=(-20,30,-30,70)+(-24.79,0,0,33)=(-44.79,30,-30,103)
\end{aligned}
$$
\[ C_{t}=\frac{-x_{0}}{(1+r)^{t}} \text { with the } \]
Then the investment flow vectors are defined by
of interest rate vector being calculated as well by using step 4 of the value of interest rate vector being calculated as well by
algorithm. $\mathrm{C}_{\mathrm{t}}=(44.79,40.72,37.02), \mathrm{K}_{\mathrm{t}}=(0.58,-0.83,1.78)$

The present value of the investment flow vector $(\mathrm{Ct})$ equals to 112.41. Finally, the value of MAIRR is $44.32 \%$. A summary of this information is provided in Table 1.

Table 1. The values of Interest Rate Vector and Value of MAIRR for cash flow $X_{26}$

\begin{tabular}{|c|c|c|c|c|c|c|}
\hline Period & 0 & 1 & 2 & 3 & $\mathrm{PV}(\mathrm{C} \mid \mathrm{r}=\%$ 5) & MAIRR \\
\hline $\mathrm{X}$ & -20 & 30 & -30 & 70 & 35.07 & \\
\hline $\mathrm{X}_{\mathrm{NEW}}$ & -44.79 & 30 & -30 & 103 & 35.07 & \multirow{2}{*}{$\% 44.32$} \\
\cline { 1 - 5 } $\mathrm{C}$ & 44.79 & 40.72 & 37.02 & 0 & 112.41 & \\
\cline { 1 - 5 } $\begin{array}{c}\text { Interest }\left(\mathrm{K}_{\mathrm{t}}\right) \\
\text { Rate }\end{array}$ & - & 0.58 & -0.83 & -1.5 & ---- & \\
\hline
\end{tabular}

As it can be observed, the present value of investment flow vector is 112.41, so the investment flow $\mathrm{Ct}$ is a net borrowing flow and due to the fact that MAIRR (i.e. 44.32) is greater than the market rate (10\%), so the project X26 would be economical.

Note: If example (A) is solved by the MAIRR method, we will reach to $15.5 \%$ for IRR which is very close to the real IRR of cash flow (15.4\%) and it is very closer to the real IRR than that of the simple arithmetic mean IRR. 
A Fuzzy Modeling for Determining Feasibility of Cash Flows Using an Efficient and Novel IRR Metric

\subsection{Rating Competitive Projects based on the proposed MAIRR Index}

To rate the competitive projects and in order to find the best economical project, the following steps are suggested:

1. Based on the steps in section 3.2, a new cash flow for all the competitive projects is defined.

2. Initial value and duration of all the new cash flows obtained from the previous step should be the same.

3. By using equation $C_{t}=\frac{-x_{0}}{(1+r)^{t}}$, the common investment flow vector is calculated from the previous step. The present value of this vector can be calculated under the market rate $r$.

4. The values of interest rate vector $(\mathrm{Kt})$ can be defined for each project.

5. The MAIRR is determined for each project.

6. If $\mathrm{PV}$ of an investment flow vector $(P V(C \mid r)$ ) is positive (negative), then a project has a higher priority with greater (smaller) MAIRR value.

Example C. Consider the following competitive projects where their present values are computed under $10 \%$ for the market rate.

$$
\begin{aligned}
& \mathrm{X}_{27}=(-100,-110,310), \operatorname{PV}\left(\mathrm{X}_{27} \mid \mathrm{r}=10 \%\right)=56.20 \\
& \mathrm{X}_{28}=(-50,50,-30,120), \mathrm{PV}\left(\mathrm{X}_{28} \mid \mathrm{r}=10 \%\right)=60.82 \\
& \mathrm{X}_{29}=(-30,80,20,-130,120), \mathrm{PV}\left(\mathrm{X}_{29} \mid \mathrm{r}=10 \%\right)=43.55
\end{aligned}
$$

In order to rank the projects by the MAIRR index, new cash flow should be calculated for all the projects.

$$
\begin{aligned}
& \mathrm{V}_{27}=(-100,0,121), \mathrm{X}_{27}+\mathrm{V}_{27}=\mathrm{X}_{\mathrm{NEW}, 27}=(-200,-110,431) \\
& \mathrm{V}_{28}=(-24.79,0,0,33), \mathrm{X}_{28}+\mathrm{V}_{28}=\mathrm{X}_{\mathrm{NEW}, 28}=(-74.79,50,-30,153) \\
& \mathrm{V}_{29}=(-97.67,0,0,0,143), \mathrm{X}_{29}+\mathrm{V}_{29}=\mathrm{X}_{\mathrm{NEW}, 29}=(-127.67,80,20,-130,263)
\end{aligned}
$$

In the following, one should put the initial value and duration of all new cash flow to be the same. For this purpose, duration of all XNEW projects must be changed to the same one.

$$
\begin{aligned}
& X_{\text {NEW }, 27}=(-200,-110,431,0,0) \\
& X_{\text {NEW }, 28}=(-74.79,50,-30,153,0) \\
& X_{\text {NEW }, 29}=(-127.67,80,20,-130,263)
\end{aligned}
$$


Hossein Ali Ghaffari, Vahidreza Ghezavati

Based on the initial values of the cash flow streams, the value of $\mathrm{Xp}$ is found -200 . Then, by defining the following operators, the initial values for all projects $X_{\text {New }}$ will be the same.

$$
\begin{aligned}
& \begin{aligned}
Z_{27} & =\left((-200-(-200), 0,0,0,0), Z_{27}+X_{N E W, 27}=(-200,-110,431,0,0)\right. \\
Z_{28} & =\left((-200-(-74.79), 0,0,0,183.32), Z_{28}+X_{N E W, 28}=(-200,50,-30,153,183.32)\right. \\
Z_{29} & =\left((-200-(-127.67), 0,0,0,105.9), Z_{29}+X_{N E W, 29}=(-200,80,20,-130,368.90)\right.
\end{aligned} \\
& \qquad C_{t}=\frac{-x_{0}}{(1+r)^{t}}, \text { the investment flow vector and its } P V \text { are }
\end{aligned}
$$
defined as below.

$$
\mathrm{C}=(200,181.82,165.29,150.26,0), \mathrm{PV}(\mathrm{C} \mid \mathrm{r}=10 \%)=614.79
$$

\begin{tabular}{|c|c|c|c|c|c|c|c|}
\hline Cash flow & 0 & 1 & 2 & 3 & 4 & $\mathrm{PV}(\mathrm{r}=\% 10)$ & MAIRR \\
\hline $\mathrm{C}$ & 200 & 181.82 & 165.29 & 150.26 & 0 & 614.79 & ----- \\
\hline $\mathrm{Z}_{27}+\mathrm{X}_{\mathrm{NEW}, 27}$ & 200 & -110 & 431 & 0 & 0 & 56.20 & \multirow[t]{2}{*}{$\% 20.06$} \\
\hline Interest Rates $\left(\mathrm{K}_{\mathrm{t}}\right)$ & ---- & -0.64 & 2.28 & -0.09 & -1.00 & ----- & \\
\hline $\mathrm{Z}_{28}+\mathrm{X}_{\mathrm{NEW}, 28}$ & $\begin{array}{c}- \\
200\end{array}$ & 50 & -30 & 153 & 183.32 & 60.82 & \multirow{2}{*}{$\% 20.88$} \\
\hline Interest Rates $\left(\mathrm{K}_{\mathrm{t}}\right)$ & ----- & -0.64 & 2.28 & -0.09 & -1.00 & ----- & \\
\hline $\mathrm{Z}_{29}+\mathrm{X}_{\mathrm{NEW}, 29}$ & 200 & 80 & 20 & -130 & 368.90 & 43.55 & \multirow{2}{*}{$\% 17.79$} \\
\hline Interest Rates $\left(\mathrm{K}_{\mathrm{t}}\right)$ & ---- & -0.64 & 2.28 & -0.09 & -1.00 & ---- & \\
\hline
\end{tabular}

Then, the interest rate vectors are calculated for each cash flow and finally the MAIRR values are calculated for all the above cash flow. A summary of this information is provided in Table 2.

Table 2. Values of Interest Rate Vector and MAIRR Value for cash flow X27-X29

Based on Table 2, ranking the projects shows the following result, which is consistent with the present value method. $X_{2}>X_{1}>X_{3}$ 
A Fuzzy Modeling for Determining Feasibility of Cash Flows Using an Efficient and Novel IRR Metric

\section{Developing proposed MAIRR method under fuzzy conditions}

In real-world conditions, the value of parameters such as incomes, investments, inflation rate, market rate, and etc may not be a certain value and it may change over the period of time (Guerra et. al., 2014). In other words, the main practical limitation in the economic evaluation of the projects is the estimation of cash flow stream values in the form of an absolute number where it is difficult for some projects and impossible for some others. This is a difficult task for some projects that are accompanied by a probable error that significantly reduces correctness of the obtained results. This inability for proper decision making on rejecting or accepting the projects might lead to huge losses for the decision makers.

Therefore, estimation of the cash flow stream is difficult and even almost impossible for some projects. For this purpose, in order to attain a higher reliability level invalidity of the results regarded to define economic feasibility and rating of the projects, fuzzy sets theory was utilized. To define and calculate the fuzzy internal rate of return (FIRR), one should first be aware of the concepts and theories of fuzzy sets.

In this paper, we aim to develop the proposed MAIRR method under the fuzzy situation in order to economic evaluation of projects. For this purpose, @RISK software will be applied. @RISK is one of the most efficient and useful applications used for simulation and implementation of many statistical analyses on the uncertain cash flow. This application generates random numbers for the uncertain values of the cash flow stream and calculates the user's desired calculations many times.

In the following, the values of cash flow streams are inserted into @RISK and the results are obtained after a hundred thousand times of simulation.

The fuzzy numbers are used when it is needed to implicitly represent the uncertainty of the numerical data. In other words, they are fuzzy sets which state the meaning of statements such as approximately 3 or close to 5.5. In fact, the fuzzy numbers include terms such as relatives, close to and not completely beside the numerical values.

\subsection{Definitions \\ 4.1.1 Vertex Method}

Vertex method was the first one developed for the evaluation of functions with fuzzy variables by Dong and Shah (2007). The fuzzy variables under $\alpha$-cut will be converted to interval variables between two real numbers. Therefore, under each cut, the functions with the fuzzy variables will be converted to the interval variables. In this paper, the vertex method will be applied to fuzziness the proposed method. 
Hossein Ali Ghaffari, Vahidreza Ghezavati

\subsubsection{Strict Exceedance Possibility}

Negi and Lee (1933) introduced strict exceedance possibility to compare fuzzy numbers. In order to be aware of this index, consider triangular fuzzy numbers $\widetilde{\mathrm{B}}=\left(\mathrm{b}_{1}, \mathrm{~b}_{2}, \mathrm{~b}_{3}\right)$ and $\widetilde{\mathrm{R}}=\left(\mathrm{r}_{1}, \mathrm{r}_{2}, \mathrm{r}_{3}\right)$. By applying strict exceedance possibility, fuzzy number $\mathrm{B}$ from $\mathrm{R}$ is:

$$
\operatorname{Poss}(\bar{B}>\bar{R})= \begin{cases}1 & \text { if } b_{2} \geq r_{3} \\ \frac{\left(b_{3}-r_{2}\right)}{\left(b_{3}-b_{2}\right)+\left(r_{3}-r_{2}\right)} & \text { if } b_{2} \leq r_{3}, b_{3} \geq r_{2} \\ 0 & \text { if } b_{3} \leq r_{2}\end{cases}
$$

\subsection{Developing proposed MAIRR method under fuzzy environment}

In this section, we aim to develop the proposed MAIRR method under fuzzy situations. As it is stated earlier, we will apply vertex method to fuzziness MAIRR method and @RISK software will be applied to run such a procedure. We will describe this procedure by an example as follows.

Fuzzy flow of the cash flow X27 (based on the example C) is considered in the following supposing that the values of f-rate and r-rate equal the fuzzy number $(20 \%, 25 \%, 30 \%)$ and that the market rate equals the fuzzy number $(15 \%, 20 \%$, $25 \%$ ).

\begin{tabular}{|c|c|c|c|c|c|}
\hline Period & $\underline{0}$ & $\underline{1}$ & $\underline{2}$ & $\underline{3}$ & $\underline{4}$ \\
\hline Cash flow & $(-40,-35,-30)$ & $(5,10,15)$ & $(10,15,20)$ & $(-460,-430,-400)$ & $(530,570,600)$ \\
\hline
\end{tabular}

At first, the fuzzy values of a cash flow stream and market rate are converted to some intervals under different cuts, and then an interval under each cut for the FIRR is obtained through the Vertex method. Interval of IRR for cash flow $\widetilde{\mathrm{X}}_{27}$ and summary of obtained intervals for IRR are described in Tables 4 and 5 , respectively.

Table 4. Interval of IRR for cash flow $\widetilde{\mathrm{X}}_{27}$ based on MAIRR Method

\begin{tabular}{|c|c|c|c|c|c|c|c|c|}
\hline Cut & Period & 0 & 1 & 2 & 3 & 4 & $\begin{array}{c}\text { Market } \\
\text { rate }\end{array}$ & MAIRR \\
\hline \multirow{4}{*}{$a=0$} & \multirow{2}{*}{$\begin{array}{l}\text { Start } \\
\text { point }\end{array}$} & -40 & 10 & -215 & 200 & 80 & $15 \%$ & $11.6 \%$ \\
\hline & & -40 & 10 & -215 & 200 & 80 & $25 \%$ & $14.5 \%$ \\
\hline & \multirow{2}{*}{$\begin{array}{l}\text { End } \\
\text { point }\end{array}$} & -30 & 20 & -200 & 250 & 110 & $15 \%$ & $29.6 \%$ \\
\hline & & -30 & 20 & -200 & 250 & 110 & $25 \%$ & $35.6 \%$ \\
\hline
\end{tabular}


A Fuzzy Modeling for Determining Feasibility of Cash Flows Using an Efficient and Novel IRR Metric

\begin{tabular}{|c|c|c|c|c|c|c|c|c|}
\hline \multirow{4}{*}{$a=0.2$} & \multirow{2}{*}{$\begin{array}{l}\text { Start } \\
\text { point }\end{array}$} & -39 & 11 & -214 & 206 & 82 & $16 \%$ & $13.6 \%$ \\
\hline & & -39 & 11 & -214 & 206 & 82 & $24 \%$ & $16.1 \%$ \\
\hline & \multirow{2}{*}{$\begin{array}{l}\text { End } \\
\text { point }\end{array}$} & -31 & 19 & -202 & 246 & 106 & $16 \%$ & $28.2 \%$ \\
\hline & & -31 & 19 & -202 & 246 & 106 & $24 \%$ & $32.7 \%$ \\
\hline \multirow{4}{*}{$a=0.4$} & \multirow{2}{*}{$\begin{array}{l}\text { Start } \\
\text { point }\end{array}$} & $\begin{array}{l}-38 \\
\end{array}$ & 12 & -213 & 212 & 84 & $17 \%$ & $15.6 \%$ \\
\hline & & -38 & 12 & -213 & 212 & 84 & $23 \%$ & $17.7 \%$ \\
\hline & \multirow{2}{*}{$\begin{array}{l}\text { End } \\
\text { point }\end{array}$} & -32 & 18 & -204 & 242 & 102 & $17 \%$ & $26.7 \%$ \\
\hline & & -32 & 18 & -204 & 242 & 102 & $23 \%$ & $29.9 \%$ \\
\hline \multirow{4}{*}{$a=0.6$} & \multirow{2}{*}{$\begin{array}{l}\text { Start } \\
\text { point }\end{array}$} & -37 & 13 & -212 & 218 & 86 & $18 \%$ & $17.7 \%$ \\
\hline & & -37 & 13 & -212 & 218 & 86 & $22 \%$ & $19.2 \%$ \\
\hline & \multirow{2}{*}{$\begin{array}{l}\text { End } \\
\text { point }\end{array}$} & -33 & 17 & -206 & 238 & 98 & $18 \%$ & $25.2 \%$ \\
\hline & & -33 & 17 & -206 & 238 & 98 & $22 \%$ & $27.2 \%$ \\
\hline \multirow{4}{*}{$a=0.8$} & \multirow{2}{*}{$\begin{array}{l}\text { Start } \\
\text { point }\end{array}$} & -36 & 14 & -211 & 224 & 88 & $19 \%$ & $19.9 \%$ \\
\hline & & -36 & 14 & -211 & 224 & 88 & $21 \%$ & $20.7 \%$ \\
\hline & \multirow{2}{*}{$\begin{array}{l}\text { End } \\
\text { point }\end{array}$} & -34 & 16 & -208 & 234 & 94 & $19 \%$ & $23.7 \%$ \\
\hline & & -34 & 16 & -208 & 234 & 94 & $21 \%$ & $24.6 \%$ \\
\hline \multirow{2}{*}{$a=1$} & $\begin{array}{c}\text { Start } \\
\text { point }\end{array}$ & -35 & 15 & -210 & 230 & 90 & $20 \%$ & $22.2 \%$ \\
\hline & $\begin{array}{l}\text { End } \\
\text { point }\end{array}$ & -35 & 15 & -210 & 230 & 90 & $20 \%$ & $22.2 \%$ \\
\hline
\end{tabular}


Hossein Ali Ghaffari, Vahidreza Ghezavati

Table 5. Summary of Obtained Intervals for IRR of cash flow $\widetilde{\mathbf{X}}_{27}$ based on fuzzy MAIRR Method

\begin{tabular}{|r|r|r|r|}
\hline$\alpha=0$ cut & $\operatorname{IRR}_{0}=[\% 11.58, \% 35.63]$ & $\alpha=0.6$ cut & $\operatorname{IRR}_{0.6}=[\% 17.71, \% 27.23]$ \\
\hline$\alpha=0.2$ cut & $\mathrm{IRR}_{0.2}=[\% 13.56, \% 32.72]$ & $\alpha=0.8$ cut & $\mathrm{IRR}_{0.8}=[\% 19.90, \% 24.65]$ \\
\hline$\alpha=0.4$ cut & $\mathrm{IRR}_{0.4}=[\% 15.60, \% 29.92]$ & $\alpha=1$ cut & $\mathrm{IRR}_{1}=[\% 22.16, \% 22.16]$ \\
\hline
\end{tabular}

Finally, connection of the intervals with each other contributes to obtain fuzzy IRR based on the proposed MAIRR method and it is indicated in Fig. 1.

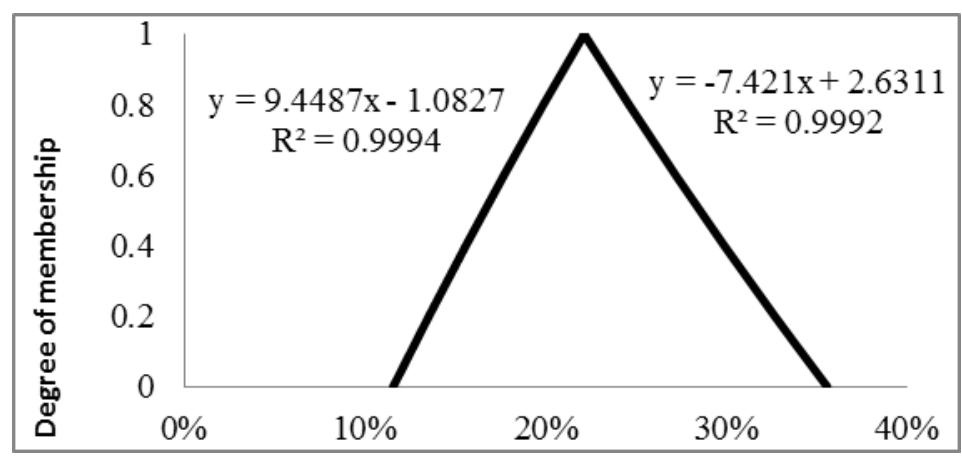

Figure 1. FIRR Diagram of cash flow $\widetilde{\mathrm{X}}_{27}$ based on the proposed MAIRR Method

Table 6. The characteristics of the proposed fuzzy MAIRR and @ Risk

\begin{tabular}{|l|c|c|c|}
\hline \multicolumn{1}{|c|}{ Method } & Min & Mean & Max \\
\hline Vertex and proposed MAIRR & $\% 11.58$ & $\% 22.16$ & $\% 35.63$ \\
\hline$@$ Risk & $\% 15.58$ & $\% 22.41$ & $\% 30.29$ \\
\hline
\end{tabular}

If a decision maker aims to estimate the FIRR based on the proposed MAIRR method as a fuzzy number, then the estimated FIRR will be equal to the triangular fuzzy number $(11.58 \%, 22.16 \%, 35.63 \%)$ based on Table 6 . This estimation based on Fig. 1 would be an appropriate approximation for FMAIRR.

To verify the economic feasibility of the cash flow stream X27, strict exceedance possibility method is applied. Estimated fuzzy MAIRR of the cash flow stream X27 is equal to the triangular fuzzy number $(11.7 \%, 21.6 \%, 33.2 \%)$ and the market rate is equal to $(15 \%, 20 \%, 15 \%)$. Because the cash flow stream $\mathrm{X} 27$ is an investment flow, strict exceedance possibility of the estimated fuzzy MAIRR is obtained from the market rate. 
A Fuzzy Modeling for Determining Feasibility of Cash Flows Using an Efficient and Novel IRR Metric

$$
\operatorname{Poss}(\overline{\mathrm{FIRR}}>\overline{\mathrm{r}})=\frac{\left(\mathrm{FIRR}_{3}-\mathrm{r}_{2}\right)}{\left(\mathrm{FIRR}_{3}-\mathrm{FIRR}_{2}\right)+\left(\mathrm{r}_{3}-\mathrm{r}_{2}\right)}=\frac{33.2-20}{(33.2-21.6)+(25-20)}=\% 79.8
$$

Therefore, it can be stated that the cash flow X27 with the degree of possibility $0.798(79.8 \%)$ is economically feasible. Now, @RISK is used to analyze the results, which are presented after hundred thousand times of simulation and illustrated in Fig. 2.

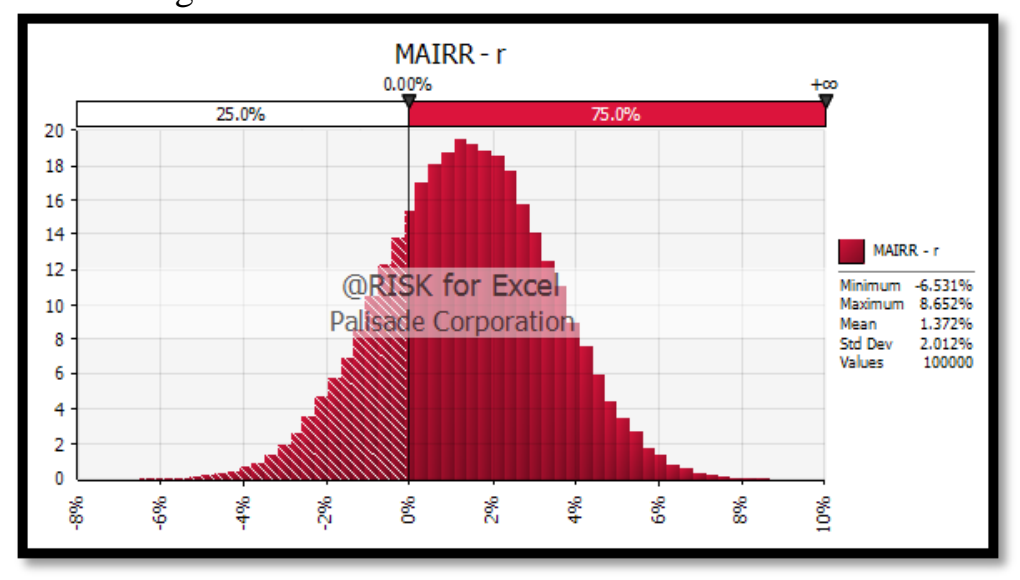

Figure 2. Diagram of IRR Difference of MAIRR Method and Market Rate by @ RISK

Based on Fig. 2, it can be stated that based on the MAIRR method and @ RISK software, the above cash flow is economical with the possibility of $75.0 \%$.

As it can be clearly observed, the obtained results of the proposed MAIRR are close to each other and imply the validity of the obtained result from the Vertex method.

\subsection{Comparison and Analysis of Results for Different Methods}

In this section, we aim to compare the performance of the proposed fuzzy MAIRR via classical fuzzy AIRR. For this purpose, the NPV method is used for a benchmark method to validate the most efficient method. Therefore, each method that is more consistent with the NPV method would be more efficient.

In order to compare the performance of the above methods to solve example X27, the NPV method is used which leads to trustworthy results. In this regard, by using application@RISK and NPV method, simulation of the above cash flow is run and finally, the results are presented below after hundred thousand times of simulation. 


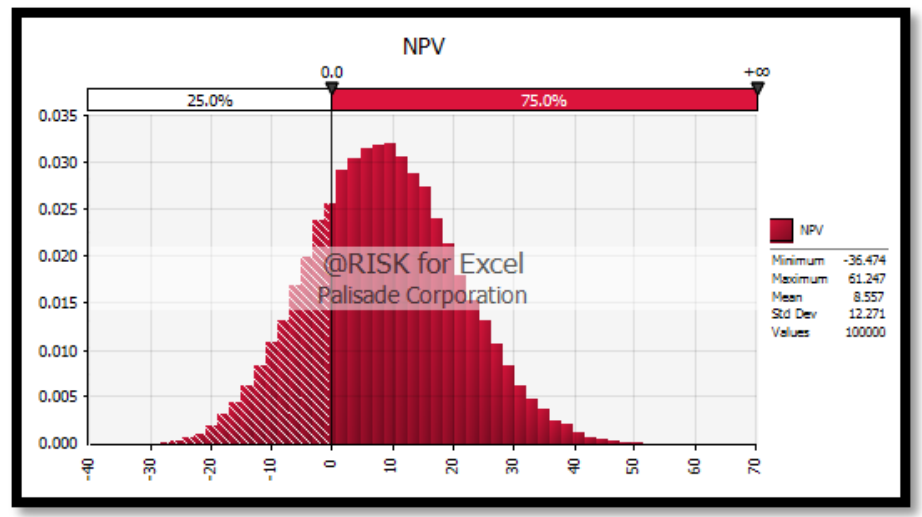

Figure 3. NPV Diagram based on @ RISK Software

Fig. 3 shows that based on the NPV method and @RISK software, the above cash flow (X27) is economical with a $75.0 \%$ degree of possibility. In the following table (Table 7), the comparison of the obtained results based on economic evaluation of the projects is presented.

Table 7. Comparison of Results of Different Method based on Economic Evaluation

\begin{tabular}{|c|c|c|c|}
\hline $\begin{array}{l}\text { Technique } \\
\text { Output }\end{array}$ & Fuzzy AIRR & Fuzzy MAIRR & Fuzzy NPV \\
\hline $\begin{array}{c}\text { Degree of Possibility of } \\
\text { Economic Feasibility } \\
\text { based on Vortex } \\
\text { Method }\end{array}$ & 95.5 percent & 79.8 percent & -- \\
\hline $\begin{array}{c}\text { Degree of Possibility of } \\
\text { Economic Feasibility } \\
\text { based on @ RISK } \\
\text { Software }\end{array}$ & 92.7 percent & 75.0 percent & 75.0 percent \\
\hline
\end{tabular}

Based on the certainty of the results from the NPV method and @RISK software, we can state that the above cash flow is $75 \%$ economically feasible. The first noteworthy point in Table 6 is that by application of @ RISK and using both methods MAIRR and NPV, the above-mentioned project is $75 \%$ feasible economically which implies consistency of the obtained results from the fuzzy MAIRR with those of fuzzy NPV method. This means that the proposed fuzzy MAIRR has a suitable performance and this is noted as one of the main advantages of this method in this paper.

Another point is that based on the methods of fuzzy AIRR algorithm and Vertex method, the probability of economic feasibility of the above-mentioned cash flow is $95.5 \%$, whereas it becomes $92.7 \%$ when the @ RISK software is used. 
A Fuzzy Modeling for Determining Feasibility of Cash Flows Using an Efficient and Novel IRR Metric

Moreover, the difference in the obtained values for the probability of economic feasibility between fuzzy AIRR (92.7\%) and fuzzy NPV methods (75\%) is attributed to the heuristic and unstable nature of AIRR method. In other words, the reason for the inconsistent probability of economic feasibility obtained from Vertex method (95.5\%) is arbitrariness and dependency of the AIRR upon selection off-rate and r-rate values which are two input parameters of AIRR method. Therefore, we can conclude that the results of this method are neither valid nor reliable in practice.

Therefore, we can state that probability of economic feasibility based on the proposed fuzzy MAIRR (79.8\%) and Vertex methods is close to $75 \%$, which shows the sufficient reliability level of the fuzzy MAIRR method to estimate numerical values of the IRR. Finally, the probability of economic feasibility of the above cash flow using @RISK and based on MAIRR and NPV methods are equal to each other which implies correctness and reliability level of the MAIRR method.

\section{Conclusions and Further Suggestions}

In this paper, we introduced a new method in which the MAIRR index led to the elimination of the problems of the IRR method and attribution of proper values to the IRR index. It should be noted that the results of this method are consistent with those of the NPV method with proper mathematical support. Also, there were no limitations to the current research. @RISK software which is based on Monte Carlo simulation is used to validate different methods. To define the economic feasibility of the cash flow, the FIRR values of each project were defined. Finding out the values of FIRR was done by conversion of all the fuzzy values of the cash flow stream under different $\alpha$-cut intervals. Afterward, Vertex method along with one of the techniques of AIRR, and MAIRR were used to calculate fuzzy values of IRR index. The result implies the validity and reliability of the proposed method. Strict exceedance possibility was then applied to define the economic feasibility of the cash flow streams by AIRR and MAIRR methods. Validation of the results was done through simulation and NPV methods. Further Suggestions: a) Analyzing the method of IRR under uncertain environments such as necessity, credibility, plausibility, and belief, b) Application of other available methods in the fuzzy sets theory to define FIRR values such as methods of solving fuzzy non-linear equations, c) Application of robust approach for analysis of the profitability of cash flow streams.

\section{REFERENCES}

[1] Appadoo, S. S., Bhatt, S. K. \& Bector, C. R. (2008), Application of Possibility Theory to Investment Decisions. Fuzzy Optimization and Decision Making, 7(1), 35-57; 
Hossein Ali Ghaffari, Vahidreza Ghezavati

[2]Bas, E. (2013), A Robust Approach to the Decision Rules of NPV and IRR for Simple Projects. Applied Mathematics and Computation, 219(11), 5901-5908;

[3]Brealey, R. A., Myers, S. C., Allen, F. \& Mohanty, P. (2012), Principles of Corporate Finance. Tata McGraw-Hill Education;

[4]Chen, I. F. \& Tsaur, R. C. (2016), Fuzzy Portfolio Selection Using a Weighted Function of Possibilistic Mean and Variance in Business Cycles. International Journal of Fuzzy Systems, 18(2), 151-159;

[5]Dong, W. \& Shah, H. C. (1987), Vertex Method for Computing Functions of Fuzzy Variables. Fuzzy sets and Systems, 24(1), 65-78;

[6]Dubois, D. J. (1980), Fuzzy Sets and Systems: Theory and Applications (Vol. 144). Academic press;

[7]Guerra, M. L., Magni, C. A. \& Stefanini, L. (2014), Interval and Fuzzy Average Internal Rate of Return for Investment Appraisal. Fuzzy Sets and Systems, 257, 217-241;

[8]Guerra, M. L. \& Sorini, L. (2012), Incorporating Uncertainty in Financial Models. Applied Mathematical Sciences, 6(76), 3785-3799;

[9]Hazen, G. (2009), An Extension of the Internal Rate of Return to Stochastic Cash Flows. Management Science, 55(6), 1030-1034;

[10]Keynes, J. M. (1937), The General Theory of Employment. The quarterly journal of economics, 51(2), 209-223;

[11]Kierulff, H. (2008), MIRR: A Better Measure. Business Horizons, 51(4), 321329.

[12]Kuchta, D. (2008), Fuzzy Rate of Return Analysis and Applications. In Fuzzy Engineering Economics with Applications (pp. 97-104). Springer, Berlin, Heidelberg;

[13]Magni, C. A. (2010a), Average Internal Rate of Return and Investment Decisions: A New Perspective. The Engineering Economist, 55(2), 150-180;

[14]Magni, C. A. (2011b), Aggregate Return on Investment and Investment Decisions: A Cash-Flow Perspective. The Engineering Economist, 56(2), 140169;

[15]Magni, C. A. (2013c). The Internal Rate of Return Approach and the AIRR Paradigm: A Refutation and a Corroboration. The Engineering Economist, 58(2), 73-111;

[16]Negi, D. S. \& Lee, E. S. (1993)., Possibility Programming by the Comparison of Fuzzy Numbers. Computers \& Mathematics with Applications, 25(9), 43-50;

[17]Osborne, M. J. (2010), A Resolution to the NPV-IRR Debate?. The Quarterly Review of Economics and Finance, 50(2), 234-239;

[18]Sari, I. U. \& Kahraman, C. (2015), Interval Type-2 Fuzzy Capital Budgeting. International Journal of Fuzzy Systems, 17(4), 635-646;

[19]Weber, T. A. (2014), On the (Non-) equivalence of IRR and NPV. Journal of Mathematical Economics, 52, 25-39;

[20]Yao, J. S., Chen, M. S. \& Lin, H. W. (2005), Valuation by Using a Fuzzy Discounted Cash Flow Model. Expert Systems with Applications, 28(2), 209- 